shows that the error of the signal to Greenwich did not exceed $0 \cdot 2^{\mathrm{s}}$ on 131 days; on 18 days the error was greater than $1 \cdot 0^{\mathrm{s}}$.

There has been a considerable increase in the amount of testing to be done at the Observatory of Admiralty chronometers and watches; additional chronometer watches will shortly be delivered for testing and purchase. The Observatory now has its own adjusting and repair shop with a small technical staff. The equipment includes an automatic watch rate recorder, by means of which a watch may be tested in all positions and its rate read off in a few seconds.

The Nautical Almanac. During the year, the Nautical Almanac for 1938 and that for 1939 have been published. The new Air Almanac has been published over an experimental period; from the experience gained, it will, from next January, appear in a completely new form in which the essential data required by the airman can be obtained with much greater ease. Because of the consequent increase in bulk, the Air Almanac for 1939 will be issued quarterly. Besides the work on these almanacs, considerable preliminary work and calculation have also been done on other publications to be issued shortly from the Office. The occultation supplement-"The Prediction and Reduction of Occultations" - was published last August and includes a complete description of the occultation machine and the new method of reduction in use at the Office. The extensive occultation predictions for 1940 have been completed.

Magnetic Observations. The mean values of the magnetic elements at Abinger for 1937 are :

\begin{tabular}{|c|c|c|c|c|}
\hline Declination, West & & .. & & $11^{\circ} 10^{\circ} 4^{\prime}$ \\
\hline Horizontal intensity & & & & 0.18522 \\
\hline Vertical intensity & & & & $0 \cdot \mathbf{4 3 0 3 1}$ \\
\hline Inclination $\quad \ldots$ & ... & $\ldots$ & $\ldots$ & $66^{\circ} 42 \cdot 7^{\prime}$ \\
\hline
\end{tabular}

During the year there were 25 magnetic disturbances reaching storm intensity, of which 3 disturbances were classified as "great storms". A La Cour magnetograph has been installed, and its value was notably illustrated by recording the extreme ranges of $D$, $H$ and $V$ during the exceptionally violent storm of April 16. The electrification of the railway line through Holmwood to Portsmouth has given rise to grave concern owing to the very marked disturbances of the traces during experimental running of trains. "If," the report adds, "disturbances of the same magnitude prove to be normal, when the regular service is in operation, it will be a matter for serious consideration whether the further continuance of magnetic work at Abinger is justifiable."

Meteorological Observations. For the twelve months ending April 30, 1938, the mean temperature was $51 \cdot 0^{\circ} \mathrm{F}$., which is $1.5^{\circ}$ higher than the average of seventy-five years 1841-1915. The month of March was the warmest March ever recorded at Greenwich, being $7 \cdot 1^{\circ}$ above the average. The total rainfall for the twelve months was $19 \cdot 50$ inches, which is $4 \cdot 74$ inches less than the average. Regular records for measurement of the amount of solid matter polluting the air have been continued as well as the measurement of the gaseous pollution of the air by sulphur dioxide. At one time, during the period November 25 -28 , the amount of solid matter reached $4 \cdot 4$ milligrams per cubic metre, that is, about $7 \mathrm{lb}$. in the volume of air contained in a cube with one hundred yards edge.

In his concluding remarks, the Astronomer Royal referred to the long series of observations made with the Airy Transit Circle-the fundamental instrument of the Royal Observatory for more than eighty-seven years. More star transits have been obtained with this instrument than with any other meridian instrument. The Prime Meridian Conference which met at Washington in 1884 recommended the adoption of the meridian passing through the centre of this instrument as the initial meridian for longitude. Even if no further observations are made with the Airy Transit Circle, it will be retained in its present position because of its historical interest.

Staff changes include the resignation of Dr. R. v. d. R. Woolley to take up the appointments of chief assistant at the University Observatory, Cambridge, and John Couch Adams astronomer in the University of Cambridge; the resignation of $\mathbf{M r}$. W. M. H. Greaves to take up the appointments of Astronomer Royal for Scotland and professor of astronomy in the University of Edinburgh ; and the retirement of Mr. C. R. Davidson after more than forty-one years of service at the Observatory. Dr. Woolley has been succeeded by Dr. R. d'E. Atkinson and Mr. Davidson by Dr. A. Hunter. Miss F. M. McBain has been appointed assistant and Mr. W. E. Candler temporary assistant at the Nautical Almanac Office.

\title{
Tides of the British Seas*
}

$\mathrm{W}$ HILE the tides generated by the sun and moon in an ocean covering the whole earth uniformly would be relatively simple in form, the actual tides are very much complicated by the distribution of the continental land masses and the irregular coast-lines.

The tides of the British seas are largely derived from the tides generated in the Atlantic Ocean. As the tidal wave enters a shallower channel like the English Channel its speed is reduced and its range increased. Consequently in the seas about the British Isles there is a larger range of tide than there is in mid-Atlantic.

- Substance of a lecture by Prof. G. R. Goldsborough, F.R.S., to the Newcastle-on-Tyne Astronomical Society, delivered on March 3 .
The earth's rotation has a considerable influence upon the form of the tidal wave. A wave running up a straight non-rotating channel with parallel sides and uniform depth would have its crests straight across the channel and of uniform height. If, however, the channel is made to rotate, the wave crests, while still straight across the channel, are no longer of uniform height, but are higher on one bank than on the other. Similarly the troughs are deeper on one bank than on the other. When the direction of propagation of the wave is reversed, the phenomenon is reversed, the higher end of each crest being now on the opposite bank. This is roughly exemplified in the English Channel, where the tidal ranges are 
higher on the French side than those on the English side; and in the St. George's Channel, where the tidal ranges are higher on the Welsh coast than on the Irish coast.

The phenomenon becomes still more interesting when, in the rotating channel, there are two sets of waves proceeding in opposite directions. The effect of uniting the two waves which will have the higher part of their crests on opposite shores is to produce a set of amphidromic points. These are points at which there is no tidal rise and fall of the water level. The points are (under uniform conditions) placed at equal distances down the centre line of the channel. Leading from each amphidromic point is a tidal crest which sweeps round the amphidromic point rather like the hand of a clock (though not necessarily straight) in the period of the tidal oscillation. The channel is thus divided up into separate, independent and similar systems. The tidal range increases as we pass from the amphidromic point outwards along the tidal crest.

The main amphidromic point in the North Sea is over the Dogger Bank, and the tidal crest sweeps down the English coast from north to south and then up the Belgian coast from south to north. A modification is made by the existence of a smaller system of the same kind in the Flemish Bight.

Similar phenomena are found in the English Channel though the amphidromic point is in Wilt. shire; and in St. George's Channel where the amphidromic point is in Wexford.

Referring to the effect of wind in altering the mean water level, both theory and observation show that the wind blowing steadily along the surface of the open sea causes a surface drift of the water in a direction inclined at $45^{\circ}$ to the right of the wind in the northern hemisphere and a general drift at $90^{\circ}$ to the right of the wind direction. In the southern hemisphere the corresponding effects are $45^{\circ}$ and $90^{\circ}$ to the left of the wind direction. The combination of a strong north-west wind with the perigean tides affords an explanation of the recent flooding of the East Anglian coasts.

\section{Child Nutrition}

\begin{abstract}
A NORTHUMBERLAND and Durham Conference on Child Nutrition, organized by the Children's Minimum Council, was held in Newcastleon-Tyne on May 14. Prof. V. H. Mottram, professor of physiology in King's College of Household and Social Science, University of London, who was one of the principal speakers, posed five questions to which the scientific nutrition expert should be able to give unequivocal answers : namely,
\end{abstract}

(1) What is meant by an adequate diet?

(2) What is the minimal cost of such a diet ?

(3) Is the cheapest adequate diet either dietetically or psychologically possible ?

(4) Even if this diet of minimal cost were practicable, could everyone afford it ?

(5) Is there indisputable evidence that many children are not able to get adequate nourishment ?

In his answer to the first question, Prof. Mottram covered dietetic ground familiar to most readers of Nature. He stressed in particular the value of milk and fruit as sources of the 'protective' factors of diet. The cheapest diet containing all the necessary constituents in adequate amounts and proper pro. portions consists of cheese, coarse brown bread and raw cabbage. This would entail no cooking and very little preparation, but would be neither easy to eat nor very digestible. One must consider not only the theoretical value of a diet as purchased but also its 'availability', satiety value and psychological effect. Hunger may be the best sauce, but monotony drives appetite away.

Even so, this primitive and unappetizing pabulum (one dare not dignify it with the title of diet) would cost at least $4 / 9$ per 'man' per week, a sum beyond the purse of more than a tenth of the population of Britain. That is, from purely theoretical considerations many people are markedly underfed, while many more-about two fifths to one half-must have dietaries lacking in some of the so-called protective foods. There is no difficulty about the supply of sufficient energy-giving foodstuffs. Calories are cheap-a thousand for a penny-but vitamincontaining foods are relatively expensive.

Is there, however, actual evidence of under. nutrition? Nutrition has been given a wider connotation in medical literature than in common speech, which from the point of view of the man-in-the-street is a pity as undefined terms or terms used to cover various meanings lead, and in this instance have led, to bitter wrangling. Using the common meaning of the word, evidence can be produced that malnutrition is too common to be neglected if we wish for a fit nation now or in the immediate future. For example, some 25 per cent of the children in or around London suffer from a lack of a fat-soluble vitamin derived from milk, butter, carrots, etc. This is shown by defective vision in twilight. Even university students, because of the absence of citrous fruit and/or fresh meat in their diet, have been known to show the signs of latent scurvy or even actual scorbutic gums. Lady Mellanby has demon. strated that bad teeth in children were to a great extent due to a low intake of the vitamin D complex found in summer milk and butter.

To some extent, these defects are being overcome by the provision of school meals and milk in schools, and by the provision of cheap or free milk to necessitous nursing mothers and their infants. There is, however, no service to cover the gap between the infant welfare period and the school age. During these three years, irreparable damage may be done. "The schools", said Prof. Mottram, "start with damaged goods"'. The process of repair is more costly than proper building and, as Lady Mellanby has proved for teeth, 'repair' generally means covering up shoddy material and jerry building with layers of good material. No matter how soundly this later building may be done, the whole structure is rotten at the core.

Miss Rathbone, M.P. for the Northern Universities, urged that immediate action should be taken to remedy this state of affairs, and dealt with the various reasons why schemes at present in operation are only partially effective.
D. B. 